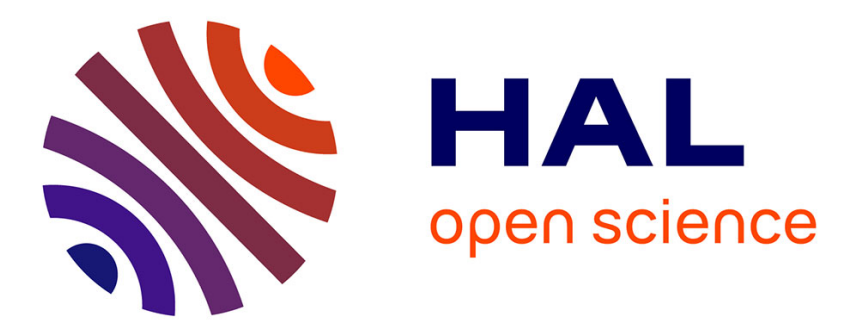

\title{
Design of a 20 MW Fully Superconducting Wind Turbine Generator to Minimize the Levelized Cost of Energy
}

Trung-Kien Hoang, Loic Queval, Christophe Berriaud, Lionel Vido

\section{- To cite this version:}

Trung-Kien Hoang, Loic Queval, Christophe Berriaud, Lionel Vido. Design of a 20 MW Fully Superconducting Wind Turbine Generator to Minimize the Levelized Cost of Energy. 13th European Conference on Applied Superconductivity (EUCAS2017), Sep 2017, Genève, Switzerland. pp.1-4, 10.1109/TASC.2018.2810309 . hal-01729944

\section{HAL Id: hal-01729944 \\ https://hal.science/hal-01729944}

Submitted on 23 Jul 2020

HAL is a multi-disciplinary open access archive for the deposit and dissemination of scientific research documents, whether they are published or not. The documents may come from teaching and research institutions in France or abroad, or from public or private research centers.
L'archive ouverte pluridisciplinaire HAL, est destinée au dépôt et à la diffusion de documents scientifiques de niveau recherche, publiés ou non, émanant des établissements d'enseignement et de recherche français ou étrangers, des laboratoires publics ou privés. 
Author's post-print (ie final draft post-refereeing) published in the IEEE Transactions on Applied Superconductivity (Jun. 2018).

(C2018 IEEE. Personal use of this material is permitted. Permission from IEEE must be obtained for all other users, including reprinting/ republishing this material for advertising or promotional purposes, creating new collective works for resale or redistribution to servers or lists, or reuse of any copyrighted components of this work in other works.

DOI: doi.org/10.1109/TASC.2018.2810309

URL: https://ieeexplore.ieee.org/document/8304612

Cite: T.-K. Hoang, L. Quéval, C. Berriaud, L. Vido, ’Design of a 20 MW fully superconducting wind turbine generator to minimize the levelized cost of energy," IEEE Transactions on Applied Superconductivity, vol. 28, no. 4, pp. 1-4, June 2018. 


\title{
Design of a 20 MW Fully Superconducting Wind Turbine Generator to Minimize the Levelized Cost of Energy
}

\author{
Trung-Kien Hoang, Loïc Quéval, Christophe Berriaud, Lionel Vido
}

\begin{abstract}
Superconducting machines are promising candidates for direct-drive multi-megawatt offshore wind turbines. Here, we designed a $20 \mathrm{MW}$ fully superconducting synchronous wind turbine generator using magnesium diboride $\left(\mathrm{MgB}_{2}\right)$ superconductors for both rotor and stator windings. $\mathrm{MgB}_{2}$ tapes operating at $10 \mathrm{~K}$ are used for the rotor windings in order to improve the packing factor. A Rutherford cable made of 91-filament $\mathbf{M g B}_{2}$ wires operating at $20 \mathrm{~K}$ is used for the stator windings in order to limit the AC losses. Two separate cryostats are considered for the stator and the rotor to increase the system reliability. Besides, to reduce the machine's weight and to simplify the cryogenic system, a toothless magnetic circuit is adopted. The goal of the 2-D finite element method based optimization was to minimize the levelized cost of energy (LCOE). Numerical results show that the adopted topology is lightweight enabling to reduce the cost of the nacelle, tower and foundation, and therefore the LCOE in comparison to a conventional generator. But the AC losses are significant, requiring at this stage of the study an impractical number of cryocoolers.
\end{abstract}

Index Terms-Superconducting generator, machine design and optimization, wind turbine, levelized cost of energy.

\section{INTRODUCTION}

D IRECT-drive generators are desirable for offshore wind farms in order to remove the maintenance costs associated with the gearbox. In addition, aiming at reducing the levelized cost of energy (LCOE), turbine nominal powers of $10 \mathrm{MW}$ and above are anticipated. Both these trends make conventional generators with copper windings and/or permanent magnets nonviable. Indeed, low-speed and hightorque conventional machines are heavy, leading to costly nacelles, towers, and foundations. But superconducting generators might be able to cope with this problem thanks to theirs compact and lightweight designs, reducing the overall wind energy conversion system (WECS) cost and therefore its LCOE.

Automatically generated dates of receipt and acceptance will be placed here; authors do not produce these dates. This work is part of the EolSupra20 project who benefited from the financial support of the Labex LaSIPS (ANR10-LABX-0040-LaSIPS) managed by the French National Research Agency under the "Investissements d'avenir" program. (Corresponding author: Loïc Quéval.)

Trung-Kien Hoang and Loïc Quéval are with the Group of electrical engineering - Paris (GeePs), CNRS UMR 8507, CentraleSupélec, UPSud, UPMC, 91192 Gif-sur-Yvette, France (e-mail: kienht26@gmail.com, loic.queval@geeps.centralesupelec.fr).

Christophe Berriaud is with IRFU, CEA Saclay, 91191 Gif-sur-Yvette, France. (e-mail: christophe.berriaud@cea.fr).

Lionel Vido is with SATIE, CNRS UMR 8029, University of Cergy Pontoise, 95000 Cergy-Pontoise, France. (e-mail: lionel.vido@u-cergy.fr).
The goal of the EolSupra20 project is to study the feasibility of $20 \mathrm{MW}$ wind turbine generators using magnesium diboride $\left(\mathrm{MgB}_{2}\right)$ for both the rotor and stator. Previous studies often focused on BSCCO or YBCO conductors, especially for the field coil. $\mathrm{MgB}_{2}$ is considered here as an alternative because it is more economic. Besides its performances increase with time, opening the way to using it at high field (about $5 \mathrm{~T}$ ).

Several conceptual designs for $10 \mathrm{MW}$ superconducting (SC) generators have been proposed recently [1]-[5]. Those designs, however, only considered a part of the system. For example, Guan et al. minimized the stack length of several 10 MW SC generator topologies [1]. Liu et al. optimized various $10 \mathrm{MW}$ SC generator structures to minimize the levelized equivalent cost of energy, which considered only the equipment cost [2]. The cooling requirements were roughly estimated and the influences of the cryostat structure on the electromagnetic design was not considered. We argue here that the cryogenic and electromagnetic designs are strongly coupled and that the design goal should be to minimize the LCOE.

In this article, a $20 \mathrm{MW}$ direct-drive fully superconducting synchronous wind turbine generator is designed using 2-D finite element analysis, and optimized to minimize its LCOE.

\section{LCOE CALCULATION}

The LCOE is calculated considering only one turbine. We assume that the turbine will be installed on a floating foundation. The LCOE estimation includes the capital and operational expenditures, as well as the decommissioning cost. The generator capital cost is obtained in the following sections. The operational expenditures, the decommissioning cost and the cost of the other components such as blades, hub, turbine shaft and bearing, power electronics, bed-plate, nacelle cover, tower, transformer and floating foundation are obtained using scaling laws [6].

\section{GENERATOR DESIGN}

The generator's nominal power is $20 \mathrm{MW}$ with a line-to-line voltage of $3.3 \mathrm{kV}$ rms. We consider a fully superconducting generator with $\mathrm{MgB}_{2}$ used for both rotor and stator windings. Considering the fact that no commercial $\mathrm{MgB}_{2}$ generators are available, some choices are made to reduce the risks in view of building a prototype. In order to simplify the cryostat design and reduce the generator's mass, a toothless magnetic circuit is selected. 


\section{A. Cryogenic system design}

A cross section of the generator detailing the adopted cryogenic system is shown in Fig. 1. A design with warm iron and two separate cryostats is adopted, the stator cryostat is static, while the rotor cryostat is rotating. A copper electromagnetic shield is placed in between to prevent high-frequency harmonics coming from the stator windings [7]. In order to reduce the radiation heat load, a radiation shield and a multilayer insulation (MLI) are installed between the windings and the vacuum walls of the cryostats.

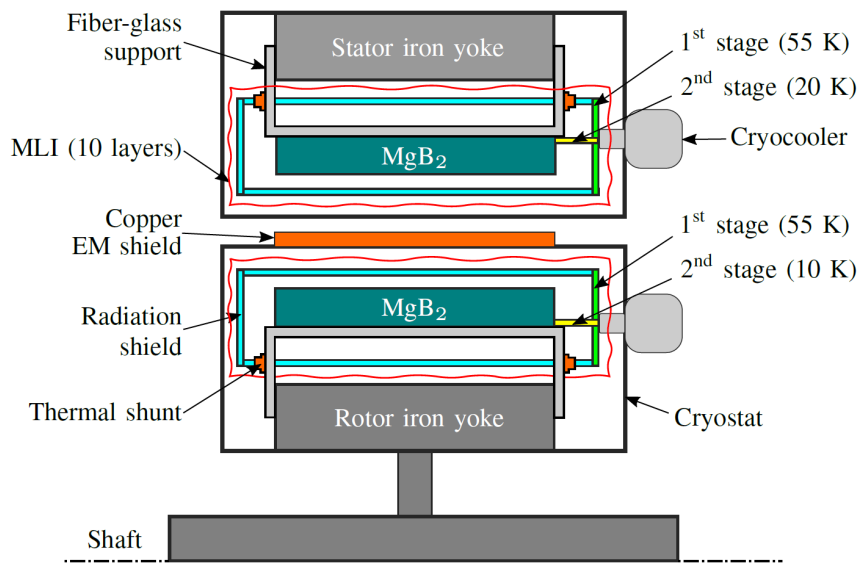

Fig. 1. Cryogenic design.

The use of two cryostats simplifies the cryostat design, but it requires a larger magnetomotive force because the magnetic air-gap length (MAL) is larger than the one that would be obtained with a single cryostat. In addition, the system reliability is improved as any failures occurring in a cryostat system will not affect the other one.

Two-stage RDK-408S2 cryocoolers from Sumitomo Heavy Industries (SHI) are selected with the cold head capacity displayed in Fig. 2. The first stage operates at $55 \mathrm{~K}$ and is connected to the radiation shield. The second stage is connected to the windings. The operating temperature of the rotor windings is set to $10 \mathrm{~K}$ to maximize the DC field. The temperature of the stator windings is set to $20 \mathrm{~K}$ to mitigate the effect of the AC losses.

\section{B. Windings design}

The $\mathrm{MgB}_{2}$ wires are different for the rotor and stator. However, for the design, we use the same characteristic for both of them (Fig. 3). We assume that the $\mathrm{MgB}_{2}$ occupies $20 \%$ of the wire cross section.

1) Rotor winding: The rotor windings are double-layer racetrack coils (DLRC). The coils are wound with $\mathrm{MgB}_{2}$ tapes $0.65 \mathrm{~mm}$ in thickness and $3.65 \mathrm{~mm}$ in width. These dimensions correspond to commercially available conductor from Columbus Superconductors (Fig. 4a). The winding packing factor is assumed to be equal to $62.5 \%$.

2) Stator winding: Here a Rutherford cable made of $\mathrm{MgB}_{2}$ wires is selected. The advantages of such a cable are high current-carrying capability and low AC losses. Although not

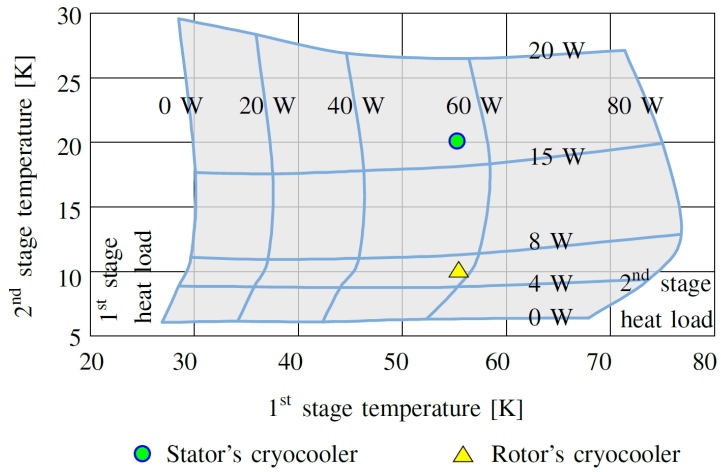

Fig. 2. Cold head capacity at $60 \mathrm{~Hz}$ of the cryocooler RDK-408S2, retrieved from SHI's datasheet. The symbols show the cryocooler operating points for the optimal design.

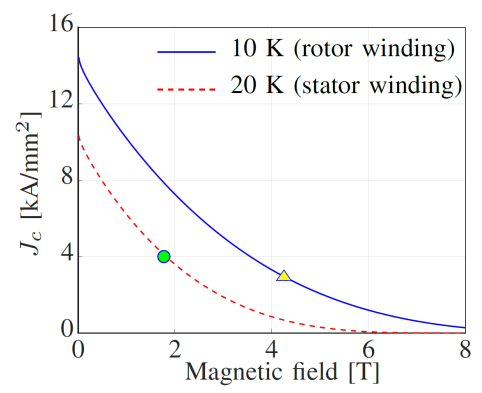

Fig. 3. Critical current density of $\mathrm{MgB}_{2}$ at various fields and temperatures. Derived from [3]. The symbols show the maximum magnetic fields of the optimal design's windings.

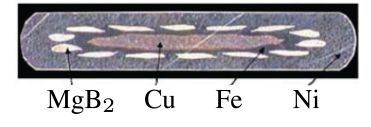

(a)

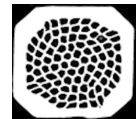

(b)

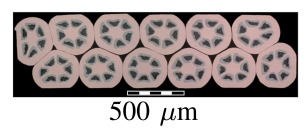

(c)
Fig. 4. Cross section of $\mathrm{MgB}_{2}$ wires and cable. (a) $\mathrm{MgB}_{2}$ tape with 14 filaments by Columbus Superconductors for the rotor windings. (b) $\mathrm{MgB}_{2}$ wire with 91 filaments for the stator windings, reproduced with permission from [8]. (c). A Rutherford cable with two layers of $\mathrm{MgB}_{2}$ wires manufactured by Hyper Tech Research, reproduced with permission from [9].

yet commercially available, such cable has already been manufactured by Hyper Tech, Inc. (Fig. 4c) [9]. According to [9], the packing factor could range from 0.79 to 0.89 . Here, the lower limit is chosen to make sure it is attainable. In order to further reduce the $\mathrm{AC}$ losses, $\mathrm{MgB}_{2}$ wires with a high number of filaments are used. Here the number of filaments per wire is set to 91 (Fig. 4b). The number of $\mathrm{MgB}_{2}$ wires per cable and the wire diameter are design variables.

\section{Electromagnetic design}

The generic generator's electromagnetic design is shown in Fig. 5. Parameters and variables are detailed in Table. I.

The 3-phase stator windings are distributed with the number of slots per pole per phase equals to $4(q=4)$. The use of toothless rotor and stator iron cores simplifies the cryostat design with the advantage of reducing the iron loss, the generator mass, and the torque ripple. For direct-drive wind generators, the cogging torque and torque ripple should be 


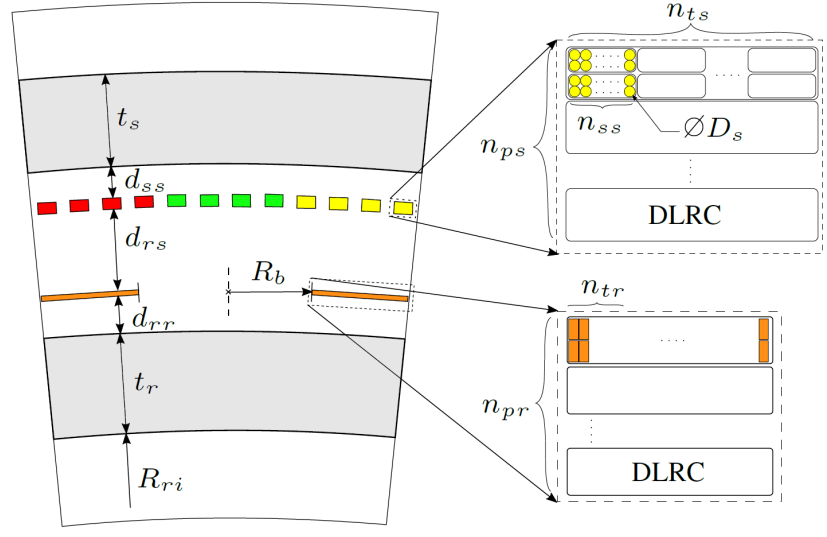

Fig. 5. One pole of the electromagnetic model.

less than $1 \%$ and $5 \%$ of the rated torque, respectively as recommended in [10].

Three design parameters $d_{r r}, d_{r s}$, and $d_{s s}$ are fixed. They strongly influence the generator design since they directly impact the MAL. An accurate calculation of these parameters would require detailed thermal and mechanical analysis. Here, we estimate that:

1) the air gap between the $\mathrm{MgB}_{2}$ or the fiber-glass support and the radiation shield is $15 \mathrm{~mm}$.

2) the thickness of the radiation shield is $5 \mathrm{~mm}$.

3) the air gap accommodating the 10-layer MLI is $20 \mathrm{~mm}$.

4) the thickness of the copper EM shield is $10 \mathrm{~mm}$ [3].

5) the thickness of the fiber-glass support is $10 \mathrm{~mm}$.

6) the thickness of the cryostat wall is $10 \mathrm{~mm}$.

With these estimations, the distance between outer rotor yoke and inner stator yoke is $225 \mathrm{~mm}$, excluding windings' heights. Another parameter shown in Fig. 5, $R_{b}$, which is the bending radius of the field coil. The minimum bending radius is calculated from the tension strain $\epsilon_{t}$ given by (1) [11, p. 6 , eq. (1)].

$$
\epsilon_{t}=\frac{r_{t}}{R_{b}+r_{t}}
$$

where $r_{t}$ is the wire radius.

In this article, $r_{t}$ is considered half of the tape thickness. The tension strain is chosen as $0.3 \%$, which is the upper limit where the critical current density remains unchanged due to the bending stresses [11]. With those assumptions, the minimum bending radius is $108 \mathrm{~mm}$.

The electromagnetic performances are calculated by using a circuit coupled 2-D finite element model with ANSYS Maxwell FEM package. In order to ensure that the generator is able to generate $20 \mathrm{MW}$ at $6.3 \mathrm{rpm}$, a purely resistive load of $0.53 \Omega$ is used.

\section{Heat LOADS CALCUlation}

The heat loads calculation is necessary to estimate the number of cryocoolers. This will influence the overall efficiency and cost of the generator. The four main sources are: the AC superconductor losses in the stator winding, the radiation losses, the current lead losses, and the conduction losses. In the first estimation, the conduction losses are assumed equal to
TABLE I

LIST OF DESIGN VARIABLES

\begin{tabular}{|c|c|c|}
\hline Symbol & Description & Optimal value \\
\hline \multicolumn{3}{|c|}{ Parameters } \\
\hline$d_{r r}$ & $\begin{array}{l}\text { Distance between the outer rotor surface and } \\
\text { inner rotor winding surface, } \mathrm{mm}\end{array}$ & 50 \\
\hline$d_{r s}$ & $\begin{array}{l}\text { Distance between the outer rotor winding sur- } \\
\text { face and the inner stator winding surface, } \mathrm{mm}\end{array}$ & 125 \\
\hline$d_{s s}$ & $\begin{array}{l}\text { Distance between the outer stator winding sur- } \\
\text { face and the inner stator yoke surface, } \mathrm{mm}\end{array}$ & 50 \\
\hline \multicolumn{3}{|c|}{ Variables } \\
\hline$p$ & Number of pole pairs & 10 \\
\hline$L_{a}$ & Stack length, m & 1.3 \\
\hline$R_{r i}$ & Inner rotor core radius, $\mathrm{m}$ & 2.5 \\
\hline$t_{r}$ & Rotor core thickness, mm & 120.3 \\
\hline$t_{s}$ & Stator core thickness, $\mathrm{mm}$ & 123.2 \\
\hline$J_{f}$ & Current density in the field's filament, $\mathrm{A} / \mathrm{mm}^{2}$ & 2276 \\
\hline$n_{t r}$ & Number of turns per rotor's DLRC & 220 \\
\hline$n_{p r}$ & Number of rotor's DLRC per winding & 1 \\
\hline$n_{t s}$ & Number of turns per stator's DLRC & 2 \\
\hline$n_{p s}$ & Number of stator's DLRCs per winding & 5 \\
\hline$D_{s}$ & Wire diameter in the Rutherford cable, $\mathrm{mm}$ & 0.8 \\
\hline$n_{s s}$ & Number of wires in the Rutherford cable & 16 \\
\hline \multicolumn{2}{|c|}{ Generator speed, rpm } & 6.3 \\
\hline \multicolumn{2}{|c|}{ Cogging torque, $\%$} & 0.03 \\
\hline \multicolumn{2}{|c|}{$U_{\text {Line-to-line voltage (rms) }}, \mathrm{kV}$} & 3.2 \\
\hline \multicolumn{2}{|c|}{ Phase current, kA rms } & 3.6 \\
\hline \multicolumn{2}{|c|}{ Output power, MW } & 20 \\
\hline \multicolumn{2}{|c|}{ Outer stator yoke diameter, $\mathrm{m}$} & 6.02 \\
\hline \multicolumn{2}{|c|}{ Generator active mass, $\mathrm{kg}$} & 44812 \\
\hline \multicolumn{2}{|c|}{ Generator inactive mass, $\mathrm{kg}$} & 122700 \\
\hline \multicolumn{2}{|c|}{ Total generator cost, $\$ \mathrm{M}$} & 5.81 \\
\hline \multicolumn{2}{|c|}{ LCOE, \$/MWh } & 140 \\
\hline
\end{tabular}

$1 \mathrm{~W}$ per winding [3], and the current lead losses are estimated as $46 \mathrm{~W} / \mathrm{kA}$ per current lead [12].

1) AC losses in the stator winding: Due to the fact that the hysteresis losses in the filaments contribute significantly to the total AC losses [13], [14], the coupling losses are neglected. The hysteresis losses per unit volume per cycle of a round filament perpendicularly placed to a magnetic field of an amplitude $B_{m}$ are expressed as (2) [13, p. 1, eq. (1)].

$$
Q_{\text {hys }}=\frac{4}{3 \pi} J_{c} d_{f} B_{m}
$$

where $d_{f}$ is the filament diameter, and $J_{c}$ is the critical current density at the magnetic field $B_{m}$

As it can be seen from (2), the hysteresis loss can be significantly reduced by increasing the number of filaments (the total filaments volume remaining constant) at the expense of increasing the manufacturing cost.

2) Radiation losses: By using more MLI layers, one can reduce the radiation losses. But the MAL will increase. However, because the thickness of one MLI layer is only $1 \mathrm{~mm}$, this increase is small compared to the MAL. Therefore, we set here the number of MLI layers to 10 (for both the rotor and stator). According to [15], a larger number of MLI layers 
will hardly reduce the radiation losses. For the radiation losses calculation, we roughly assume losses of $2 \mathrm{~W} / \mathrm{m}^{2}$ at $55 \mathrm{~K}$, and $50 \mathrm{~mW} / \mathrm{m}^{2}$ at $10 \mathrm{~K}$ and $20 \mathrm{~K}$.

\section{OPTIMIZATION AND RESULT DISCUSSION}

\section{A. Optimization approach}

The optimization problem is formulated as (3a)-(3f).

$$
\begin{array}{ll} 
& \text { Minimize } F(X)=\mathrm{LCOE} \\
& X=\text { Variable set } \\
\text { s.t. } & P_{n} \geqslant 20 \mathrm{MW} \\
& U_{\text {line-to-line }(\mathrm{rms})}=3.3 \mathrm{kV}^{ \pm 5 \%} \\
& R_{b} \geqslant 108 \mathrm{~mm} \\
& J_{f} \leqslant 0.8 J_{c f}\left(\text { at } B_{\mathrm{f}-\max }\right) \\
& J_{a} \leqslant 0.8 J_{c a}\left(\text { at } B_{\mathrm{a}-\max }\right)
\end{array}
$$

where $P_{n}$ is the nominal power, $J_{c f}$ and $J_{c a}$ are critical current densities of the $\mathrm{MgB}_{2}$ filaments at maximum flux densities $B_{\mathrm{f}-\max }$ and $B_{\mathrm{a}-\max }$ in the rotor and stator windings, respectively.

The iron losses are neglected in the optimization process since this calculation is time consuming, and importantly, the total iron losses are negligible compared to the cryocoolers power consumption. This assumption will be verified with the optimal design. In order to calculate the LCOE, loss calculations at the low wind speed region are needed. At this low wind speed region, a cryocooler is still required to operate at its full load. The power electronics loss is calculated by using a scaling law $[16$, p. 3 , eq. (3)].

\section{B. Optimal design and discussion}

The optimization is performed by using the Particle Swarm Optimization (PSO) algorithm with 500 particles and 30 iterations. The computation time is 45 hours with parallel computing on a quad-core, $2.7 \mathrm{GHz}$ computer. The features of the optimal generator are summarized in Table. I, Table. II, and Table. III. Note that, there is only one DLRC in the rotor and stator windings, because the optimization tends to reduce the MAL. The obtained LCOE is $140 \$ / \mathrm{MWh}$. The same methodology applied to design a conventional $20 \mathrm{MW}$ permanent magnet synchronous generator (PMSG) gives a LCOE of $152 \$ / M W h$. The difference is explained by the fact that the total mass of the superconducting generator is about 178 tons, which is significantly smaller than the 453 tons of the PMSG.

The total iron losses are $3.6 \mathrm{~kW}$, this negligible value confirms the validity of hypotheses that the iron losses are not considered in the optimization. The overall efficiency at 20 MW is $96.8 \%$. The flux density map is displayed in Fig. 6 with the local maximum flux density occurring at the rotor windings' edges (reported in Fig. 3). This could be avoided by using circumferentially fragmented rotor windings, making it possible to increase the average rotor field.

Note that, having cryocoolers on the rotor is challenging, a system with rotary joint could be a solution [17]. Moreover, 85 cryocoolers are required to absorb the heat losses (mainly the AC losses), this seems to be impractical. Any solutions to reduce the number of cryocoolers is of interest. For example,
TABLE II

MGB $_{2}$ WINDING CHARACTERISTIC

\begin{tabular}{llllll}
\hline & Mass $[\mathrm{kg}]$ & Length $[\mathrm{km}]$ & Cost $[\$ \mathrm{M}]$ & $J / J_{c}^{(*)}$ & $B_{\max }[\mathrm{T}]$ \\
\hline Rotor & 674 & 37 & 0.48 & $2.28 / 3.27$ & 4.02 \\
Stator & 402 & 104 & 0.29 & $3.17 / 3.94$ & 1.84 \\
\hline
\end{tabular}

${ }^{(*)}$ Current density $\left[\mathrm{kA} / \mathrm{mm}^{2}\right]$ in filaments.

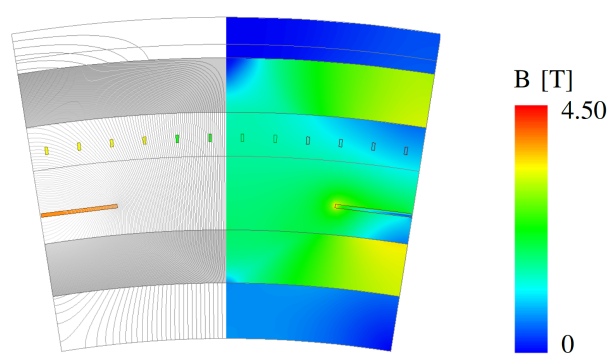

Fig. 6. Field distributions of a pole of the optimal design.

one could use a central refrigerator. But in comparison to cryocoolers, it is more expensive, more complex and less reliable. Another option is to use stator teeth to reduce the magnetic flux density in the stator windings and therefore the $\mathrm{AC}$ losses with all the drawbacks discussed earlier.

TABLE III

LOSS CALCULATION

\begin{tabular}{lll}
\hline Parameter & Rotor [W] & Stator [W] \\
\hline Winding AC losses & 0 (assumed) & $615(20 \mathrm{~K})$ \\
Conduction losses & $20(10 \mathrm{~K})$ & $240(20 \mathrm{~K})$ \\
Current lead losses, $(55 \mathrm{~K})$ & 99 & 497 \\
Radiation losses $(55 \mathrm{~K})$ & 79 & 22 \\
Radiation losses & $5(10 \mathrm{~K})$ & $6(20 \mathrm{~K})$ \\
Iron losses & 0 & $3600(300 \mathrm{~K})$ \\
\hline First stage losses, 50\% margin, $(55 \mathrm{~K})$ & 268 & 929 \\
Second stage losses, 50\% margin & $37(10 \mathrm{~K})$ & $1291(20 \mathrm{~K})$ \\
Number of cryocoolers, one spare & 8 & 77 \\
Cryocoolers power consumption & 60000 & 577500 \\
\hline
\end{tabular}

\section{CONCLUSION}

A $20 \mathrm{MW}$ fully superconducting generator using $\mathrm{MgB}_{2}$ for both rotor and stator windings has been designed and optimized. A special attention has been devoted to the cryogenic system. In comparison to a conventional PMSG, it is 2.5 times lighter. This reduces the cost of the tower and foundation, resulting in a decrease of its LCOE by $8.5 \%$. However, a large number of cryocoolers would be required making this solution impractical at this stage of the study. This problem is expected to be mitigated along with the development of the cyrocooler technology, i.e., more power and efficient cryocoolers. In future works, a thorough consideration of $\mathrm{AC}$ losses and cryogenic requirements is needed to solve this problem. 


\section{REFERENCES}

[1] Y. Guan, Z. Q. Zhu, G. J. Li, Z. Azar, A. S. Thomas, F. Vedreno-Santos, and M. Odavic, "Influence of pole number and stator outer diameter on volume, weight, and cost of superconducting generators with ironcored rotor topology for wind turbines," IEEE Transactions on Applied Superconductivity, vol. 27, no. 6, pp. 1-9, Sept 2017.

[2] D. Liu, H. Polinder, A. B. Abrahamsen, and J. A. Ferreira, "Topology comparison of superconducting generators for 10-MW direct-drive wind turbines: Cost of energy based," IEEE Transactions on Applied Superconductivity, vol. 27, no. 4, pp. 1-7, June 2017.

[3] S. S. Kalsi, "Superconducting wind turbine generator employing $\mathrm{MgB}_{2}$ windings both on rotor and stator," IEEE Transactions on Applied Superconductivity, vol. 24, no. 1, pp. 47-53, Feb 2014.

[4] Y. Terao, M. Sekino, and H. Ohsaki, "Electromagnetic design of $10 \mathrm{MW}$ class fully superconducting wind turbine generators," IEEE Transactions on Applied Superconductivity, vol. 22, no. 3, p. 5201904, June 2012.

[5] A. B. Abrahamsen, N. Mijatovic, E. Seiler, T. Zirngibl, C. Treholt, P. B. Norgard, N. F. Pedersen, N. H. Andersen, and J. Ostergard, "Superconducting wind turbine generators," Superconductor Science and Technology, vol. 23, no. 3, pp. 1-8, 2010.

[6] T. K. Hoang, L. Quéval, L. Vido, and C. Berriaud, "Impact of the rotor blade technology on the levelized cost of energy of an offshore wind turbine," in 2017 International Conference on Optimization of Electrical and Electronic Equipment (OPTIM) 2017 Intl Aegean Conference on Electrical Machines and Power Electronics (ACEMP), Brasov, Romania, May 2017, pp. 623-629.

[7] L. Quéval and H. Ohsaki, "AC losses of a grid-connected superconducting wind turbine generator," IEEE Transactions on Applied Superconductivity, vol. 23, no. 3, p. 5201905, June 2013.

[8] R. Flükiger, $M g B_{2}$ Superconducting Wires: Basics and Applications, ser World Scientific series in applications of superconductivity and related phenomena, 2016
[9] L. Kopera, P. Kovac, M. Kulich, T. Melisek, M. Rindfleisch, J. Yue, and I. Husek, "Critical currents of Rutherford $\mathrm{MgB}_{2}$ cables compacted by two-axial rolling," Superconductor Science and Technology, vol. 30, no. 1, p. 015002, 2017.

[10] R. Dutta, K. Ahsanullah, and F. Rahman, "Cogging torque and torque ripple in a direct drive interior permanent magnet generator," Progress in Electromagnetics Research B, vol. 70, pp. 73-85, 2016.

[11] K. Konstantopoulou, A. Ballarino, A. Gharib, A. Stimac, M. G. Gonzalez, A. T. P. Fontenla, and M. Sugano, "Electro-mechanical characterization of $\mathrm{MgB}_{2}$ wires for the superconducting link project at CERN," Superconductor Science and Technology, vol. 29, no. 8, p. 084005, 2016.

[12] R. Pasquet, "Contribution au développement des aimants supraconducteurs $\mathrm{MgB}_{2} \mathrm{R} \& \mathrm{~W}$ refroidis par conduction solide.” Ph.D. dissertation, Université Pierre et Marie Curie, Paris, Aug. 2015 (in French)

[13] G. Volpini, F. Alessandria, G. Bellomo, P. Fabbricatore, S. Farinon, U. Gambardella, J. Kaugerts, G. Moritz, M. Sorbi, and M. N. Wilson, "Low-loss NbTi rutherford cable for application to the SIS-300 dipole magnet prototype," IEEE Transactions on Applied Superconductivity, vol. 18, no. 2, pp. 997-1000, June 2008.

[14] N. Magnusson, S. Lindau, H. Taxt, and M. Runde, "Coupling currents and hysteresis losses in $\mathrm{MgB}_{2}$ superconductors," Superconductor Science and Technology, vol. 27, no. 10, p. 105003, 2014.

[15] M. S. Kim, Y. S. Choi, and D. L. Kim, "Variable temperature cryostat for cryogenic temperature sensor calibration," Progress in Superconductivity and Cryogenics, vol. 14, pp. 46-49, 2012.

[16] H. Polinder, F. F. A. van der Pijl, G. J. de Vilder, and P. J. Tavner, "Comparison of direct-drive and geared generator concepts for wind turbines," IEEE Transactions on Energy Conversion, vol. 21, no. 3, pp. 725-733, Sept 2006.

[17] S. Oguri, J. Choi, M. Kawai, and O. Tajima, "Cryogenic cooling with cryocooler on a rotating system," Review of Scientific Instruments, vol. 84,2013 